\title{
Mechanisms of oxide dependent tribological behavior in Ti / Steel sliding and influence of nanostructured surfaces
}

\author{
Pierre Maurel* $^{1,2,3}$, Laurent Weiss ${ }^{1}$, Philippe Bocher ${ }^{2}$, Eric Fleury ${ }^{1,3}$, Thierry Grosdidier ${ }^{1,3}$ \\ ${ }^{1}$ Laboratory of Microstructure Studies and Mechanics of Materials (LEM3), Lorraine University, CNRS UMR 7239, Metz, France \\ ${ }^{2}$ Laboratoiry of Optimisation of Advanced Processes and Fabrication (LOPFA), École de Technology Supérieure, Montréal, Canada \\ ${ }^{3}$ LABoratory of EXcellence Design of Alloy Metals for low-mAss Structures (LABEX-DAMAS), Metz, France
}

\begin{abstract}
$\underline{\text { Abstract }}$
The tribological behavior of pure titanium having coarse-grained or nanostructured surfaces has been investigated against a steel ball moved with an alternative motion. The nanostructures were obtained by Surface Mechanical Attrition Treatment (SMAT) both at room and at cryogenic temperatures. An unexpected wear behavior was revealed: the hard steel ball was abraded for all cases even if it was several times harder compared to the Ti surface. This was due to the formation of a third body consisting of hard Ti oxides. Interestingly, important variations of the coefficient of friction were also revealed during the rubbing process. These variations could be separated into three successive stages, each with its specific wear mechanisms. The wear regimes were related to changes in the third body layer formed between the Ti and steel surfaces. SMAT changed the formation kinetics of the third body. The temperature at which the SMAT was conducted also introduced different third body formation kinetics. Important variations in the formation kinetics of the third body. The temperature at which the SMAT was
\end{abstract}

\section{Introduction}

Severe Plastic Deformation (SPD) processes are widely used in order to produce nanostructured materials with enhanced several mechanical properties such as hardness or strength at the cost of a lower ductility[1,2]. Cryogenic temperatures (CT) have been used with several SPD processes and provided with further grain refinement than when ( SMAT uses a confined chamber where shots of several millimeters in diameter are propelled by a (6) After a sufficient number of impacts, a microstructure gradient was obtained towards the depth of the treated material with a nanostructure at the top surface.

The tribological properties of nanostructured alloys [7,8] and also of materials with microstructure gradients produced by severe surface plastic deformation [9-12] have already been investigated. For nanostructured titanium, some authors reported an impressive decrease in the coefficient of friction at the beginning of the tribology test [9]. Other authors did not observe such modifications for a similar Ti nanostructured surface [7]. Little explanations, if any, were given to identify the reason behind this difference, thus getting a better understanding of this tribo-system seems an important issue.

The SMAT process produces a high roughness hardly suitable for tribology applications. However, SMAT carried out at CT reduced substantially the roughness while also increasing the hardness [13]. SMAT at CT could thus be tested as an interesting way to further improve the tribological properties. In this context, the aim of the present contribution is to determine the effect of SMAT, both at RT and CT, on the tribological behavior of Ti when rubbing on a steel counterface.

\section{Materials and experiments}

A commercially pure titanium T50A ([wt\%]: Fe 0.02, C $0.005, \mathrm{O} 0.16, \mathrm{~N} 0.002$ and Ti balance was used for this investigation. Disks having a 30 mm diameter and a thickness of $10 \mathrm{~mm}$ thick samples were polished down to a 2000 grit and three conditions were prepared:

- Initial coarse-grained samples left as is after the 2000 grit polishing (Initial).

- Polished samples treated by surface mechanical attrition treatment at room temperature (SMAT-RT).

- Polished samples treated by surface mechanical attrition treatment at cryogenic temperature (SMAT-CT).

SMAT was carried out with a vibrating Stressonic device commercialized by SONATS [14]; within a treatment chamber developed by Novelli et al. [15]. The samples were treated during $10 \mathrm{~min}$ at $20 \mathrm{~mm}$ from the vibrating part, which moved at a frequency of $20 \mathrm{kHz}$ for a $60 \mu \mathrm{m}$ amplitude. Cryogenic temperature treatments were conducted with a sample holder cooled with liquid nitrogen.

Tribology tests were conducted on an Anton-Paar TRB ${ }^{3}$ pin-on-disk tribometer. The contact between a 6 mm diameter AISI 52100 steel ball ( 840 HV) and the sample followed a linear motion over $10 \mathrm{~mm}$ with a $2 \mathrm{~N}$ load and a frequency of $0.5 \mathrm{~Hz}$. The sinusoidal sliding speed reaches a maximum of $16 \mathrm{~mm} / \mathrm{s}$ in the middle of the groove length. The acquisition frequency was $50 \mathrm{~Hz}$ and the tests were carried out under ambient air at room temperature.

Microhardness measurements were made on the top surface with a $500 \mathrm{gf}$ load. The surface roughness was measured with a stylus surface profilometer. The grooves topologies were acquired by focus-variation microscopy with an Alicona Infinite Focus apparatus, it allowed to measure effectively the wear volume loss. Raman spectroscopy was conducted with a Horiba Raman HR Evolution apparatus, using an Oxxius laser at $532 \mathrm{~nm}$.

\section{$\underline{\text { Results }}$}

Fig 1 shows the SEM observation of the cross-section of the SMAT-RT sample before the tribology test. A gradient microstructure can be seen (Fig 1a): coarse grains at the core (bottom) and smaller grains within $100 \mu \mathrm{m}$ from the surface (top). Consistently with previous investigations [16], a nanostructure (Fig 1b) is generated within $30 \mu \mathrm{m}$ from the surface. The worn area depth made during the tribology tests varied between tests: 7 to $16 \mu \mathrm{m}$ for Initial, 10 to $26 \mu \mathrm{m}$ for SMAT-RT and 18 to $34 \mu \mathrm{m}$ for SMAT-CT. Most of the worn area remained within the $30 \mu \mathrm{m}$ thick nanostructured region. The core microstructure was composed of equiaxed grains with a size of about $40 \mu \mathrm{m}$. 

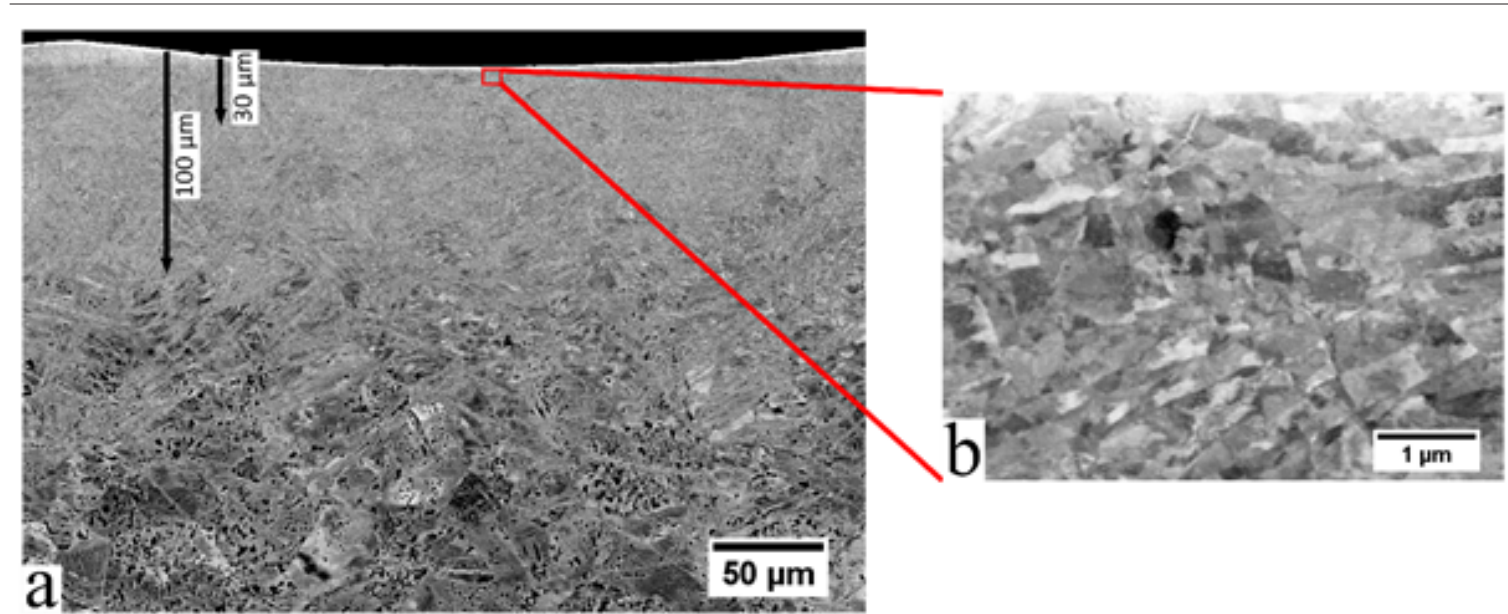

Figure 1: SEM cross-section microstructure of the SMATed sample (a) and focus on the top surface microstructure (b) made in a previous work [17]

Fig 2 a, b and c. show typical examples of the evolution of the coefficient of friction during the tribology test of T50 as a function of the number of cycles on the initial, SMAT-RT and SMAT-CT samples, respectively. All the tests shared some similar trends for the general evolution of the coefficients of friction. The coefficient of friction quickly reaches a steady-state regime in which its value remains around 0.5 , this is called hereafter stage I. Stage II begins when important fluctuations appear, ending thereby the steady-state regime. Then, the coefficient of friction reaches a local minimum just after a slow decrease, marking the beginning of stage III. Stage III is characterized by a new steady-state regime with only a very slow and continuous increase of the coefficient of friction. T1 and T2 correspond respectively to the transition times between stage I and stage II and between stage II and stage III. Large discrepancies in T1 and T2 times were however revealed within the results of each given condition.
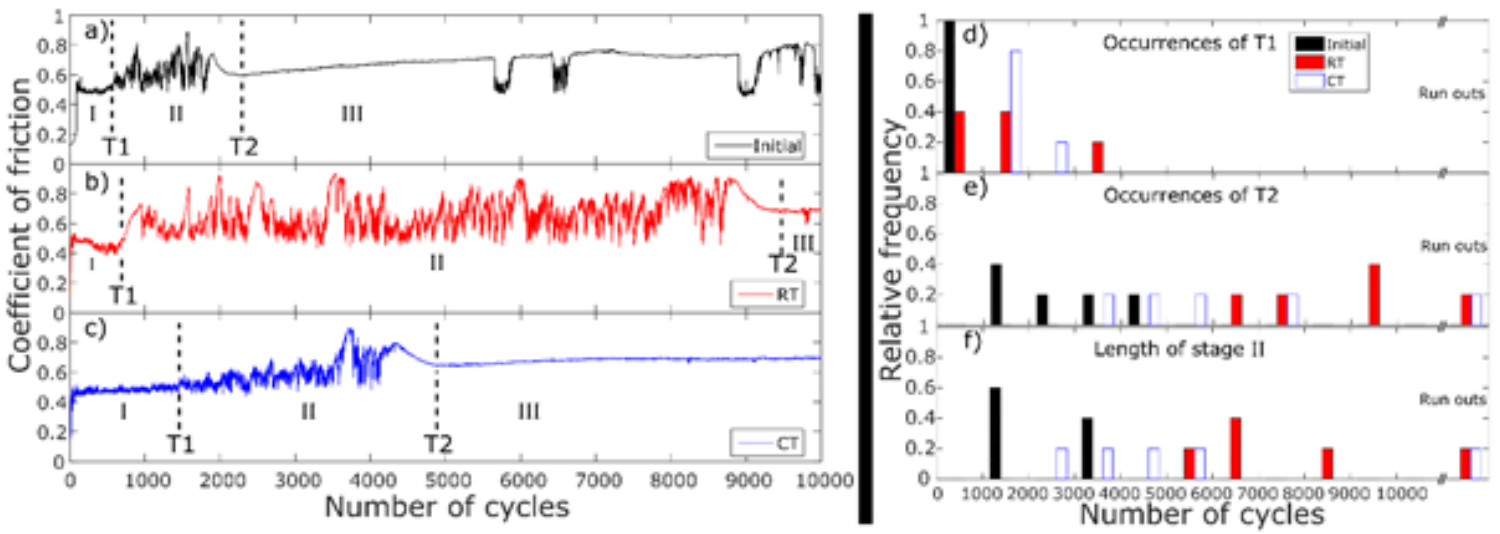

Figure 2: Coefficient of friction as a function of the number of cycles for initial T50 (a) and after SMAT RT (b) and CT (c). Histograms of the relative frequencies of the transition occurrences between stages ( $(\mathrm{a}$ and e respectively for $\mathrm{T} 1$ and $\mathrm{T} 2$ ) and of the length of stage $\mathrm{II}(\mathrm{f})$ as a function of the number of cycles.

Although discrepancies were noted, the analyses of five samples of each condition allowed to determine trends for each condition. The results are given in Fig. $2 \mathrm{~d}$, e, and $\mathrm{f}$ in the form of histograms with 1000 cycles bin width. T1 always occurs before 1000 cycles for the initial coarse-grained sample. In comparison, friction against the nanostructured SMATed samples showed a broader range for the instability appearances. SMAT-RT had the largest range from less than 1000 cycles to over 3000 cycles while the SMAT-CT range was shorter with T1 between 1000 and 3000 cycles. For the initial coarse grain sample, the length of stage II was also generally shorter than for the SMATed samples so that the number of cycles to reach T2 was also reduced. When comparing the SMATed conditions, the length of stage II was shorter and T2 appeared earlier for the SMAT-CT condition.

SMAT carried out at RT and CT generated an increase of the top surface hardness by around $50 \%$, as seen in Table 1, CT treatment produced a slightly higher hardness. Table 1 also gives the surface roughness in the form of Ra (arithmetical mean deviation of the profile) and Rz (average of the heights between the five highest peaks and lowest valleys). SMAT-RT resulted in a 20 times increase of both $\mathrm{Ra}$ and $\mathrm{Rz}$ values when compared to the polished initial surfaces, whereas SMAT-CT was more limited with a factor around 8. Finally, Table 1 gives the volume losses measured after 10000 cycles of sliding tests ( $200 \mathrm{~m}$ of total sliding distance). The initial coarse-grained surface showed the best wear resistance for the titanium surface. Its volume loss was divided by 2 and nearly 3 compared to that of the SMAT-RT and SMAT-CT surfaces, respectively. Interestingly, the Rz value of SMAT - RT is comparable to the typical depth of the wear tracks measured after the tribology tests in several other studies [9,18]. This had a potential effect on the high discrepancies of the wear volume recorded for SMATed surfaces.

\begin{tabular}{|c|c|c|c|c|c|}
\hline \multirow{2}{*}{ Sample } & \multirow{2}{*}{ Temperature $\left({ }^{\circ} \mathrm{C}\right)$ during treatment } & \multicolumn{3}{|c|}{ Before friction } & \multirow{2}{*}{\begin{tabular}{|c|} 
After friction \\
Volume loss $\left(\mathrm{mm}^{3}\right)$ \\
\end{tabular}} \\
\hline & & Surface hardness $\left(\mathrm{HV}_{0.5}\right)$ & $\mathrm{Ra}(\mu \mathrm{m})$ & $\mathrm{Rz}(\mu \mathrm{m})$ & \\
\hline Initial & 1 & $188 \pm 5$ & $0.13 \pm 0.01$ & $1.11 \pm 0.33$ & $0.0357 \pm 0.0057$ \\
\hline SMAT-RT & 20 to 80 & $282 \pm 6$ & $2.78 \pm 0.04$ & $20.19 \pm 1.87$ & $0.0699 \pm 0.0232$ \\
\hline SMAT-CT & -170 to -120 & $302 \pm 14$ & $1.22 \pm 0.17$ & $8.08 \pm 0.92$ & $0.0968 \pm 0.0343$ \\
\hline
\end{tabular}

A significant volume loss of the steel ball was observed during the tribology tests. Estimations from SEM observations of these volume losses are reported in Table 2 along the stage reached when the test was stopped. The volume loss of the steel ball was six times higher when it slid for 2000 cycles against the titanium initial surface as compared to the SMATed surfaces. This same value ( 2000 cycles against the initial surface) was still higher than the ball wear after 10000 cycles against the SMATed surfaces. Both friction tests against the SMATed surfaces were still in stage II after 2000 cycles while against the initial surface it had already reached stage III. After 2000 cycles the steel ball volume loss against both SMATed surfaces was similar whereas, after 10000 cycles, the wear recorded against the SMATed-CT was nearly twice as high. At the end of the test, the stage III friction duration against the SMAT-CT sample was twice higher than that against the SMAT - RT sample.

Table 2: Steel ball volume loss in $\mathrm{mm} 3$ and corresponding stage after 2000 and 10000 cycles

\begin{tabular}{|c|c|c|}
\hline \multirow{2}{*}{ Sample } & \multicolumn{2}{|c|}{ Ball volume loss $\left(\mathrm{mm}^{3}\right)$ and stopping stage } \\
\hline & 2000 cycles & 10000 cycles \\
\hline
\end{tabular}




\begin{tabular}{||c||c||c||}
\hline Initial & $15.4 \mathrm{e}-3$ - in stage III for 400 cycles & $28.0 \mathrm{e}-3$ - in stage III for 8000 cycles \\
\hline \hline SMAT-RT & $2.47 \mathrm{e}-3$ - in stage II for 1300 cycles & $8.36 \mathrm{e}-3$ - in stage III for 3 300 cycles \\
\hline \hline SMAT-CT & $2.16 \mathrm{e}-3$ - in stage II for 1100 cycles & $14.4 \mathrm{e}-3$ - in stage III for 6500 cycles \\
\hline \hline
\end{tabular}

Raman analyses made after each stage revealed the presence of $\mathrm{TiO}_{2}$-rutile in stage $\mathrm{II}$, a titanium oxide obtained from the $\mathrm{TiO}_{2}$-anatase present during stage $\mathrm{I}$. Further details may be found in a previous work [17]. Anatase transforms into rutile only after having been submitted to sufficiently elevated temperature (over $\left.500{ }^{\circ} \mathrm{C}\right)[19]$. TiO ${ }_{2}$-anatase is the standard titanium oxide formed at ambient temperature and has a hardness of 616-698 $\mathrm{HV}_{100}$ whereas $\mathrm{TiO}_{2}$-rutile has a hardness of 894-974 $\mathrm{HV} \mathrm{H}_{100}$ [20]. These analyses also reported the presence of several Fe-oxides: $\mathrm{Fe}_{2} \mathrm{O}_{3}$-maghemite $\left(920 \mathrm{HV}_{100}\right)$ and $\mathrm{Fe}_{2} \mathrm{O}_{3}$-hematite $\left(1000-1100 \mathrm{HV}_{100}\right)$ in the Stages II and III.

\section{$\underline{\text { Discussion }}$}

Significant wear of the steel ball counterface was noted after the tests even if the steel hardness was much higher than that of the titanium surface (i.e. 840 HV against 188 $\mathrm{HV}, 282 \mathrm{HV}$ or $302 \mathrm{HV}$ respectively for the initial coarse-grained Ti sample, the nanostructured SMAT-RT and SMAT-CT samples). The Raman analysis suggests that this is attributed to the thermally driven formation of the high hardness $\mathrm{TiO}_{2}$-rutile oxide during the friction tests.

The nature modifications of the oxides formed during the friction from Ti-rich oxides $\left(\mathrm{TiO}_{2}\right.$-anatase, $\mathrm{TiO}_{2}$-rutile) to $\mathrm{Fe}$-rich oxides $\left(\mathrm{Fe}_{2} \mathrm{O}_{3}\right.$-maghemite, $\mathrm{Fe} \mathrm{O}_{2}$-hematite $)$ explained the changes in the coefficient of friction. Each change in oxide, as seen in Fig. 1, affected the wear behavior and led to three different successive friction stages. Each stage is described below:

- The stage I - The coefficient of friction showed a gradual and steady increase of the coefficient of friction. It was accompanied by the titanium surface wear generating $\mathrm{TiO}_{2}$-anatase oxides. The $\mathrm{TiO}_{2}$-anatase was then transformed into $\mathrm{TiO}_{2}$-rutile; inducing the appearance of stage II.

- The stage II - The wear of the steel ball was explained by the hard $\mathrm{TiO}_{2}$-rutile debris formation and this led to Fe-rich oxides formation. The significant fluctuations of the coefficient of friction were then recorded. The additional formation of $\mathrm{Fe}_{2} \mathrm{O}_{3}$-hematite produced a Fe-rich oxide transfer layer on the titanium surface; initiating the stage III.

- The stage III - A stable coefficient of friction was established as the contact area corresponded to the steel ball sliding against the Fe-rich transfer layer formed on the Ti-surface. This third body oxide layer was then acting as a kind of protective layer on the Ti surface and the wear was found to correspond to removal from the steel counterface with formation of additional $\mathrm{Fe}$ and Fe-rich oxides debris.

As the transition between the different nature of oxides was essentially thermally driven, the different wear stages were affected by the Ti surfaces microstructure. The nanostructured Ti surface due to SMAT improved the mechanical properties in terms of hardness but provided with limited plastic deformation and, thus, lowered the local heat generation. Consequently, the occurrence of the transitions between the various stages was delayed as shown in Fig 2.

Under similar testing conditions, the nanostructured surfaces led to counter-intuitive wear behavior. Indeed, as the formation of hard abrasive oxides was delayed when rubbing was executed on the harder SMATed nanostructured surfaces, the wear of the steel ball counterface was consecutively reduced for the same test duration (Table 2) These hard Fe-oxides ultimately produced a third body protective layer on the Ti surfaces. The delayed formation of the protective third body onto the SMAT-RT nanostructured Ti surfaces led titanium wear losses at least twice higher compared to those obtained for steel ball sliding against the softer Ti surface (Table 1). Even though the SMAT-CT produced an increased hardness and lowered roughness, the increased brittleness led to a higher wear rate of the titanium surface (Table 1). While the similar time of $\mathrm{T} 1$ occurrences of both conditions showed that $\mathrm{TiO}_{2}$-rutile appeared roughly at the same time, the faster groove formation of $\mathrm{CT}$ treated samples trapped more efficiently the hard oxides in between the surfaces. This eventually led to a faster appearance of stage III with higher wear of the steel ball.

\section{Conclusion}

This study aimed to improve the understanding of the wear mechanism and friction behavior for the contact between commercially pure titanium surface having a different microstructure and a steel ball. The friction behavior revealed significant variations that could be attributed to the thermally-driven progressive formation of different oxides layers at the interface, first Ti-oxides and afterward protective Fe-oxides. This change in oxide nature also led to a progressive transition from the titanium surface wear to the steel ball surface wear.

Nanostructured surfaces produced by SMAT modified the formation kinetics of these oxides, slowing the wear transition process. Indeed, the friction against SMATed surfaces showed lower wear of the steel ball, but at the cost of higher titanium wear. Interestingly, although SMAT-CT conditions produced both a higher hardness and a much lower roughness, it had the worst wear resistance of both titanium and steel surfaces. The surface high brittleness allowed the faster formation of a well-formed groove, leading to higher titanium wear. This groove trapped more efficiently hard oxides accelerating the steel wear.

\section{Acknowledgements}

Funding: This work was supported by the French Government through the program "Investissements d'avenir" operated by the French National Research Agency (ANR) and referenced to as ANR-11-LABX-0008-01 ('LabEx DAMAS'). This work was also supported by the Laboratory of Optimization of Advanced Processes and Fabrication (LOPFA, Montréal, Canada).

Raman measurements were performed at the spectroscopy platform of the LMOPS, Université de Lorraine \& CentraleSupélec.

\section{References}

[1] Estrin Y, Vinogradov A. Extreme grain refinement by severe plastic deformation: A wealth of challenging science. Acta Mater 2013;61:782-817. doi:10.1016/j.actamat.2012.10.038.

[2] Lowe TC, Valiev RZ. The use of severe plastic deformation techniques in grain refinement. JOM J Miner Met Mater Soc 2004;56:64-8. doi:10.1007/s11837-004-0295-z.

[3] Ovid'ko IA, Valiev RZ, Zhu YT. Review on superior strength and enhanced ductility of metallic nanomaterials. Prog Mater Sci 2018;94:462-540. doi:10.1016/j.pmatsci.2018.02.002.

[4] Bagheri S, Guagliano M. Review of shot peening processes to obtain nanocrystalline surfaces in metal alloys Review of shot peening processes to obtain nanocrystalline surfaces in metal alloys. Surf Eng 2009;25:3-14. doi:10.1179/026708408X334087.

[5] Grosdidier T, Novelli M. Recent Developments in the Application of Surface Mechanical Attrition Treatments for Improved Gradient Structures: Processing Parameters and Surface Reactivity. Mater Trans 2019;60:1344-55. doi:10.2320/matertrans.MF201929.

[6] Lu K, Lu J. Nanostructured surface layer on metallic materials induced by surface mechanical attrition treatment. Mater Sci Eng A 2004;375-377:38-45. doi:10.1016/j.msea.2003.10.261 
[7] Wang CT, Gao N, Gee MG, Wood RJK, Langdon TG. Effect of grain size on the micro-tribological behavior of pure titanium processed by high-pressure torsion. Wear 2012;280-281:28-35. doi:10.1016/j.wear.2012.01.012.

[8] Edalati K, Ashida M, Horita Z, Matsui T, Kato H. Wear resistance and tribological features of pure aluminum and Al-Al2O3composites consolidated by high-pressure torsion. Wear 2014;310:83-9. doi:10.1016/j.wear.2013.12.022.

[9] Alikhani Chamgordani S, Miresmaeili R, Aliofkhazraei M. Improvement in tribological behavior of commercial pure titanium (CP-Ti) by surface mechanical attrition treatment (SMAT). Tribol Int 2018;119:744-52. doi:10.1016/j.triboint.2017.11.044.

[10] Sun Y. Sliding wear behaviour of surface mechanical attrition treated AISI 304 stainless steel. Tribol Int 2013;57:67-75. doi:10.1016/j.triboint.2012.07.015.

[11] Liu Y, Jin B, Li DJ, Zeng XQ, Lu J. Wear behavior of nanocrystalline structured magnesium alloy induced by surface mechanical attrition treatment. Surf Coatings Technol 2015;261:219-26. doi:10.1016/j.surfcoat.2014.11.026.

[12] Xia S, Liu Y, Fu D, Jin B, Lu J. Effect of Surface Mechanical Attrition Treatment on Tribological Behavior of the AZ31 Alloy. J Mater Sci Technol 2016;32:1245-52. doi:10.1016/j.jmst.2016.05.018

[13] Novelli M, Bocher P, Grosdidier T. Effect of cryogenic temperatures and processing parameters on gradient-structure of a stainless steel treated by ultrasonic surface mechanical attrition treatment. Mater Charact 2018;139:197-207. doi:10.1016/j.matchar.2018.02.028.

[14] SONATS Europe Technologies group. Sonats 2019. http://www.sonats-et.fr/.

[15] Novelli M, Fundenberger JJ, Bocher P, Grosdidier T. On the effectiveness of surface severe plastic deformation by shot peening at cryogenic temperature. Appl Surf Sci 2016;389:1169-74. doi:10.1016/j.apsusc.2016.08.009.

[16] Zhu KY, Vassel A, Brisset F, Lu K, Lu J. Nanostructure formation mechanism of $\alpha$-titanium using SMAT. Acta Mater 2004;52:4101-10. doi:10.1016/j.actamat.2004.05.023.

[17] Maurel P, Weiss L, Bocher P, Fleury E, Grosdidier T. Oxide dependent wear mechanisms of titanium against a steel counterface: Influence of SMAT nanostructured surface. Wear 2019;430-431:245-55. doi:10.1016/j.wear.2019.05.007.

[18] Wen M, Wen C, Hodgson PD, Li YC. Tribological behaviour of pure Ti with a nanocrystalline surface layer under different loads. Tribol Lett 2012;45:59-66. doi:10.1007/s11249-011-9862-y.

[19] Hanaor DAH, Sorrell CC. Review of the anatase to rutile phase transformation. J Mater Sci 2011;46:855-74. doi:10.1007/s10853-010-5113-0.

[20] Anthony JW, Bideaux RA, Bladh KW, Nichols MC. Handbook of Mineralogy. vol. 1. Chantilly: Mineralogical Society of America; 1990. doi:10.1016/S00162361(99)00011-3 